\title{
GROUP PRACTICE PREPAYMENT: AN APPROACH TO DELIVERING ORGANIZED HEALTH SERVICES
}

\author{
Jerry Phelan, Robert Erickson and Scott Fleming*
}

From one perspective the American way of delivering health care is uniquely un-American. As a nation we proudly consider organizational ability and a capacity for innovative response to changing conditions as hallmarks of our national character. Yet our prevailing arrangements for delivering health care are substantially without effective organization; they have not improved in proportion to advances in medical science and technology; and they have proven inadequate reasonably to assure timely delivery of appropriate health care services to the people who need them. We have an impressive health care technology, and we have a population that desires and, in fact, is demanding its benefits, but in between something is missing. Conspicuously absent are organized delivery arrangements which embody effective incentives to providers of care to match health care resources to health care needs. ${ }^{1}$

Group practice prepayment plans represent an approach to organizing health care resources that is compatible with advances in medical science and technology and that in varying circumstances has mitigated a number of the problemsincluding sharply-rising costs, insufficient manpower, and inappropriate use of facilities-that are comprised in what has come to be called the crisis in American health care. Of course, there is no one solution that will satisfy all needs, and group

* The authors are on the legal staff of Kaiser Foundation Health Plan, Inc.

1 That American health care is not well organized is a fact subject to periodic rediscovery. In $x 967$ the National Advisory Commission on Health Manpower reported:

"Medicine has participated in the general explosion of science and technology, and possesses cures and preventives that could not have been predicted even a decade ago. But the organization of health services has not kept pace with advances in medical science or with changes in society itself. Medical care in the United States is more a collection of bits and pieces (with overlapping, duplication, great gaps, high costs, and wasted effort), than an integrated system in which needs and efforts are closely related."

I National Advisory Commission on Health Manpower, Report 3 (Ig67) [hereinafter cited as Heasth Manpower Report]. Fifteen years earlier another Presidential Commission reached a similar conclusion:

"The genius for organization, so characteristic of American life in general, is conspicuous in health services by its absence. By organization is meant the process of putting together people and facilities, and utilizing them in the most efficient manner. . . .

“. . . In reality most of the American people grope their way through a haphazard array of health services ...."

I President's Commisston on the Health Needs of the Nation, Butroing America's Heatth 29 (1952) [hereinafter cited as BuILdING AMERICA's Health]. Twenty years prior to that report-in r932the landmark study by the Committee on the Cost of Medical Care are concluded, "Many of the difficulties in present medical practice can be overcome, wholly or in part, by group organization in medicine." Comamtief on the Cost of Medical Care, Medical Care for the American People ro8 (Report No. 28, 1932). 
practice prepayment is not offered as a cure-all. It is not the only way, but it is a good way.

This article identifies the principal characteristics of group practice prepayment plans $^{2}$ and provides some information about the six currently operating plans which have more than 50,000 members. It emphasizes a number of policy considerations relating to proposals for national health insurance that have particular relevance to organizations that undertake to unite and coordinate delivery of the many and varied services that constitute complete health care.

Our experience and identity is with the Kaiser-Permanente Medical Care Program, and we write from that vantage point, or with that bias.

\section{Characteristics of Group Practice Prepayment Plans}

\section{A. The Pattern of Care}

The most significant characteristic of group practice prepayment plans is acceptance of responsibility for the organization and delivery of health care services for a defined population. This function is fundamentally different from the undertakings of insurance companies or of other types of prepayment plans, which process and pay claims for the benefits specified in their contracts; the usual health care coverage offered by these organizations is solely a financial arrangement, and the persons covered must seek and find care on their own. A person who elects to enroll in a group practice prepayment plan, on the other hand, elects the pattern of care that the plan provides. ${ }^{3}$

The pattern of care under group practice prepayment has some important limitations. The most obvious are the plan's geographical limitations and the necessary limitation of the patient's choice of physician to those physicians who participate in the plan. Other disadvantages of group practice prepayment plans are more difficult to evaluate. A plan that is large enough to realize the advantages of rational

\footnotetext{
${ }^{3}$ For a brief but fairly comprehensive discussion of group practice prepayment and a number of the representative plans in 1965 , see Yedidia, Types of Health Risk Bearers: Group Practice Prepayment Plans, in Group InsURance Handbook 272 (R. Eilers \& R. Crowe eds. 1965). Other works containing a general discussion of the subject are $H$. \& A. Somers, Doctors, PAtuents, and Health Insurance 341-63 (196I); W. MacCold, Group Practice and Prepayment of Medical Care (I966); 2 Building AMerica's Health, stipra note $I$, at 240-46. Of historical significance is M. Shadid, Crusading Doctor: My Fight for Cooperative Medicine (I956). For a bibliography, see Group Practice Section, Healith Economics Branch, Drvision of Medical Care Administration, U.S. Public Health Service, Sezected References on Group Practice ( 1967 ). A recent and quite detailed discussion relating to group practice prepayment plans is found in Note, The Role of Prepaid Group Practice in Relieving the Medical Care Crisis, 84 Harv. L. Rev. 887 (r97r).

'In the San Francisco Bay area the Kaiser-Permanente Medical Care Program engages the services of seven to eight health care personnel for each 1000 members. Blue Cross, Blue Shield, and commercial insurance companies, on the other hand, do not engage personnel to provide health services to their beneficiaries. Similarly, the Kaiser-Permanente Medical Care Program has extensive facilities both for in-hospital and out-of-hospital health care, whereas indemnity programs have no health care facilities.
} 
organization and the available economies of scale may become impersonal and may be no less frustrating to deal with than any other large enterprise. It is one thing to organize resources for health care, but sometimes it is quite another to have the organizational design produce the desired result of personalized, accessible, and effective health services.

This pattern of care also has important advantages. Group practice prepayment plans seek to enhance health and the quality of medical care by encouraging the patient's early consultation with a physician and by encouraging referrals to specialists by physicians who, because they have ready access to specialists and do not stand to lose a fee, have no incentive or obligation to practice outside of their professional capacity. ${ }^{4}$ One of the most significant factors contributing to the quality of care is the process of selection of medical group members by other physicians on the basis of education and professional competence and the continuing review and evaluation of the performance of participating physicians by other physicians. In many groups board-certified or board-qualified specialists predominate, and participation in clinical research and in continuing education programs and teaching is common. ${ }^{6}$

Most plans cover both professional and hospital services, while some provide professional services only. Of the plans covering hospitalization, some operate their own hospitals while others arrange hospitalization for their members in community hospitals. Most hospital-based plans participate in intern and residency programs approved by the American Medical Association's Council on Medical Education and Hospitals, and the hospitals themselves are accredited by the Joint Commission on Accreditation of Hospitals.

The full potential of group practice prepayment can be achieved only in hospital-based plans with inpatient and outpatient services integrated in one setting. Equipment and supporting personnel which often would be prohibitively expensive for solo practitioners or small groups can be shared and more fully utilized at medical centers serving large and coordinated groups of physicians. Physicians and professionally trained nurses can concentrate their time and skills on patient care, free from conflicting nonprofessional tasks which can be performed by less highly trained personnel. More complete medical records available to all participating physicians can be maintained in one place.

Most often the participating physicians are organized as an independent medical group, while in other plans the physicians are employees. We believe that pro-

\footnotetext{
'See Cutting, Medical Care: Its Social and Organizational Aspects-Group Medical Practice and Prepayment, 269 N. ENG. J. MEd. 729 (I963).

2 Health Manpower Report, stpra note $x$, at 204-05; A. Weissman, The Kaiser Foundation Medical Care Program, address before the annual meeting of the Society of Internal Medicine, Denver, Colo., Mar. 3I, 1963 (copy in the files of Kaiser Foundation Health Plan, Inc.).

${ }^{\circ}$ For example, about $85 \%$ of The Permanente Medical Group's physicians are certificd specialists, and $10 \%$ of them hold university teaching hospital appointments. The Permanente Medical Group serves Kaiser-Permanente members in northern California.
} 
fessional status is enhanced by a separate and independent medical group. Service is better when the physicians devote their full professional time to the plan's members.

While assumption of the responsibility for organizing and delivering services is the most important distinguishing feature of group practice prepayment plans, other characteristics have great significance. These include (I) voluntary enrollment, (2) compensation of physicians on a basis other than fee-for-service, (3) comprehensiveness of benefits, and (4) community rating.

\section{B. Voluntary Enrollment}

Individual and self-pay group subscribers to group practice prepayment plans enroll voluntarily and are free to withdraw from membership at any time simply by failing to make required payments. People entitled to coverage under a group health benefits program, paid for fully or partially by an employer or health and welfare fund, frequently are assured freedom of choice through dual choice or multiple choice arrangements. ${ }^{7}$ Under these arrangements, each person eligible for benefits under the health benefits program is offered a choice between a group practice prepayment plan and one or more other types of plans such as those provided under Blue Cross, Blue Shield, or commercial insurance. These other types of plans, unlike group practice prepayment plans, permit unrestricted choice of hospitals and physicians. Periodically the beneficiaries of the group have an option to select one of the alternate plans offered. The periodically renewed right to choose from among significantly different types of prepayment programs means that each subscriber may select the program that is most satisfactory to him and that he may transfer to another plan if dissatisfied. ${ }^{8}$

The general policy of many group practice prepayment plans, following a concept established by the Kaiser-Permanente Medical Care Program, ${ }^{9}$ is to participate in a group health benefits program only if the beneficiaries are given this choice. Under Kaiser's experience, in a few instances this preferred policy cannot be followed because potential alternate carriers, applying conventional insurance concepts, decline to participate because they regard the group as too small or as otherwise involving too great an underwriting risk. In these rare instances the Kaiser program is the only plan available to the group's beneficiaries.

Dual choice has advanced the interests of the plans and the welfare of their members in a number of ways. First, availability of a choice of plans has blunted

\footnotetext{
${ }^{7}$ See Yedidia, Dual Choice Programs, 49 Am. J. Pub. Heartr I475 (I959); Hearings on S. 94 Before the Subcomm. on Insurance of the Senate Comm. on Post Office and Civil Service, 86th Cong., Ist Sess. 219-23 (1959).

"Although "freedom of choice" generally is regarded as a plus, a somewhat contrary view has been expressed that in some instances this freedom should be subordinated to the responsibility of the group purchaser of health benefits to assure a good medical care program. R. Munts, Bargaining for HEALTF 214-19 ( 1967$)$.

${ }^{\circ}$ H. \&. A. Sonsers, supra note 2, at 35 I.
} 
criticism of group practice prepayment plans for not providing free choice of physician. ${ }^{10}$ Second, by introducing group practice prepayment plans as an alternative to the incumbent carrier, rather than as a replacement, group practice prepayment plans have found it easier to gain acceptance. Dual choice also introduces a competitive element that gives all participating plans a continuing incentive to respond to the needs of the people they serve. Finally, dual choice provides a means for avoiding the member dissatisfaction that inevitably surfaces when people are captives of a system, particularly a system they do not like.

\section{Compensating the Physicians}

Another significant feature of group practice prepayment plans is the pooling of physician income and the distribution of this income according to a prearranged formula that does not relate income to specific services performed. Under the dominant pattern a nonprofit corporation (such as Kaiser Foundation Health Plan, Inc.) contracts with the plan's members to arrange specified health care services. This commitment usually is fulfilled by means of a contract between the corporation and an independent group of physicians organized as a partnership, association, or professional corporation. The payment from the corporation to the group of physicians commonly is established on a per capita basis-a fixed monthly payment for each member of the plan that does not vary with the amount of service provided. This approach represents a sharp departure from the traditional and still dominant fee-for-service system. By altering the straight-line relationship between service performed and income received, group practice prepayment plans remove incentives to perform unneeded services and encourage use of the most appropriate services. The natural consequence of this approach is emphasis upon preventive care and early detection of illness.

\section{Comprehensive Benefits}

Comprehensive benefits ${ }^{11}$ are important for a number of reasons. First, comprehensive benefits are what people need and increasingly expect. Second, comprehensive

\footnotetext{
${ }^{10}$ The benefits of "free choice of physician" may have been oversold. As one veteran of group practice prepayment has observed, this freedom may amount to no more than "an obligation imposed on an unenlightened patient to choose from an unlabeled product." C. B. Esselstyn, The Outlook for Group Practice-Prepayment, Direct Service Plans During the Next 20 Years, address before the Michigan State Medical Society, 1966, at to (copy in the files of Kaiser Foundation Health Plan, Inc.). Too often a person's right to select his own physician is implemented by getting advice from his neighbor or by looking in the yellow pages for a physician who is located nearby or who has a name that sounds reliable. Group practice prepayment plans, on the other hand, provide a mechanism for screening and continuing evaluation of each physician in the group by his peers.

${ }^{11}$ No prepaid health care arrangement provides total coverage, and the word "comprehensive" when used to describe health benefits is always used in a relative sense. Items not usually covered, or only partially covered, include dental care, psychiatric care, and outpatient preseription drugs. Under the Federal Employees Health Benefits Act of 1959, the U.S. Civil Service Commission may approve "Group-practice prepayment plans which offer [certain designated health benefits], in whole or in substantial part on a prepaid basis, with professional services thereunder provided by physicians practicing as a group in a common center or centers. Such a group shall include physicians repre-
} 
coverage removes or minimizes the financial barriers to the patient in seeking care, thereby promoting early consultation, early detection, and early treatment. Third, as the range of prepaid benefits is broadened, the physician has greater freedom to prescribe the care for his patient that is medically appropriate. ${ }^{\mathbf{1 2}}$

Making comprehensive care available in an ordered setting in which the incentives are pointed in the right direction helps assure "appropriate utilization"-a concept that involves not only the nature of the service to be provided but also the volume of service and the place (such as hospital or medical office) where it is provided. As stated by the National Advisory Commission on Health Manpower,

Prepayment and comprehensive care appear to be major keys to Kaiser's ability to control medical care utilization. Prepayment permits a contract arrangement that eliminates incentive for physicians to provide unnecessary medical procedures, and inclusion of outpatient care in the Kaiser benefit package eliminates members' financial incentives to undergo unnecessary hospitalization. ${ }^{13}$

....

... In the final analysis, it is the individual physician who has the most influence on the cost of medical care. It is he who determines how much and what kind of medical services the members receive. Kaiser has been able to achieve substantial savings because it has been able to get individual physicians to control the costs of providing medical care. The Kaiser physicians operate in a setting which makes them constantly aware of the costs associated with providing medical services and which exerts pressure on them to avoid waste. ${ }^{14}$

senting at least three major medical specialties who receive all or a substantial part of their professional income from the prepaid funds."

5 U.S.C. $\$ 8903(4)$ (A) (Supp. IV, r969). A summary of benefits available during r967 under four plans participating in the Federal Employees Program is set forth in Somers, What Price Comprehensive Care?, i7 Archr. Environ. Heatith 6 (Ig68).

${ }^{13}$ Historically the trend in the insurance industry has been to cover hospitalization first, followed by surgical coverage, and then regular medical and major medical coverage. Development in this sequence is traceable in part to the concept that insurability depends upon unpredictability of the insured casualty, while the basic services-office calls, drugs, diagnostic laboratory, and $\mathrm{x}$-ray servicescould be budgeted by most families without application of the risk-spreading principle. On a more practical level, the insurance industry was not anxious to process a large volume of relatively small claims, and the requirement that the patient pay a portion of the cost of his care was thought to inhibit utilization.

However, providing coverage according to these concepts introduced artificial compartmentalization of health services, particularly with respect to "in-hospital" versus "out-of-hospital" services. Both patients and physicians came to think in terms of having a service fit within a covered rather than an uncovered compartment, with resulting practical limitations on the physician's freedom to select the most appropriate service. For example, early in the development of hospital insurance plans it became clear that when certain services (such as $\mathrm{x}$-ray and laboratory services) were covered only for hospitalized patients, there was a strong tendency to hospitalize patients for these services even though they could be provided equally well on an outpatient basis. Similarly, a patient with broad hospital benefits but no other institutional coverage may be retained in the general hospital even though another institution could provide appropriate care at lower cost. Exclusion of psychiatric coverage does not necessarily free a plan from providing psychiatric care; a psychiatric problem may be manifested through an ostensibly organic complaint, and psychiatric care is provided under some other label.

Further, the need for all health services is random and unequal. An individual family's need for the basic services referred to may require expenditures not easily budgeted, and risk-spreading is an appropriate means for handling the costs of these services.

122 HeALTH MANPOWER REPORT, supra note I, at 208.

16 Id. at 216. See also $x$ id. at 66-68; Medical Advisory Council to the Board of Administration 
Further, an obligation to provide comprehensive benefits includes a correlative opportunity to maximize effective organization of a broader spectrum of health services. This permits, at least theoretically, fuller realization of the organizational and economic advantages of a coordinated and integrated approach to health care. It also involves the people who serve the plan's members in an endeavor that is rooted in the community and designed to serve broad individual and community needs.

\section{E. Community Rating ${ }^{15}$}

Community rating involves charging similar rates to all groups with similar benefits, irrespective of the group's actual or prospective utilization of services. ${ }^{16}$ This approach contrasts with experience rating, which relates each group's rates to its utilization of services, with the result that some groups pay more than others for the same contract benefits.

Community rating helps assure a measure of stability in membership and income that could not be achieved if rates were to fluctuate with changes in utilization. A stable and predictable income is required to meet the substantial fixed and semifixed costs involved in providing health care or in standing ready to provide it. Similar predictability is required in planning for facilities and personnel to serve membership growth. It is not possible to develop overnight the personnel and facilities required to serve an unanticipated growth in membership, nor is it possible to dismantle overnight a service capability that is created to serve a membership growth that does not occur.

Experience rating by a group practice prepayment plan would move it toward fee-for-service, with its incentive to maximize fees by maximizing services. ${ }^{17}$ Experience rating also entails a substantial score-keeping endeavor that is costly, contributes nothing to care, and soon becomes an end in itself. Further, if experience rating were to price some members out of the market for plan coverage, the plan

of the Public Employees' Rettrement System, Final Report on the Survex of Consumer Experience Under the State of California Employees' Hospital and Medical Care Act (i968); Perrott, Utilization of Hospital Services, 56 AM. J. PuB. Health 57 (1966); Perrott \& Chase, The Federal Employees Health Benefits Program, Group Health Welfare News, Special Supp., May ig67, at 1 .

${ }^{15}$ See A. Weissman, Rationale of Community Rating by Kaiser Foundation Medical Care Program, presentation to the Hawaii Labor-Management Committee on Health Care, Oct. 14, x969 (copy of outline in files of Kaiser Foundation Health Plan, Inc.); Weissman, Achieving a Balanced Membership in Health Plans, in Proceedings of Tenth Anndal Group Hearth Institute 60-65 (Group Health Association of America, 1960).

${ }^{18}$ In order to avoid adverse selection, enrollment of non-group members may be subject to medical review. When dealing with a broad range of groups, however, it may be reasonably assumed that the persons eligible for coverage are representative of the community generally with respect to their present and prospective health care requirements, and there is no corresponding need for a medical revicw requirement.

17 "Group health plans do not feel that the best interests of the patient, in particular, or health, in general, are served when physicians are remunerated on the traditional fee-for-service or piecework basis. The principle of piecework was invented as an incentive to encourage the production of more pieces."

Address by C. B. Esselstyn, supra note Io, at II. 
could lose its broad-based character and become a plan for special, "low-risk" groups. Ultimately the plan's community character would be destroyed.

II

\section{Growth of Group Practice Prepayment}

\section{A. Obstacles}

Although group practice prepayment plans have demonstrated their ability to control costs and to offer their members an organized approach to delivery of appropriate services, these plans in the main have not enjoyed spectacular growth. ${ }^{18}$ A number of reasons for their modest growth rate may be mentioned.

First, health care in the United States has no strong organizational tradition, and development of a group practice prepayment plan requires departure from the established system by institutions and the population to be served, and particularly by physicians. What incentive do they have to change? Fee-for-service, solo practice provides the individual physician with a good income, independence, professional acceptance, and standing in the community. There may be a crisis in American health care, but there is no crisis for the individual physician. The system works well for him.

Moreover, any disinclination to depart from traditional practice has been supported by the organized profession, which historically has not been a positive force for constructive change in organization and delivery of health care services. ${ }^{19}$ In 1958, however, the Commission on Medical Care Plans of the American Medical Association submitted a report (commonly called the Larson Report after the Commission's Chairman, Leonard W. Larson, M.D.) which devoted considerable space to "Miscellaneous and Unclassified Plans," including group practice prepayment plans. The Commission reaffirmed that free choice of physician was an important factor in providing good medical care, but it also stated,

In the closed-panel, direct service, type of plan visited, the committee has uniformly observed care of good quality being made available to patients who do not have "free choice of physician" in the literal sense of the term. This is possible when sponsors of these plans have accepted their obligation to see that plan physicians are well qualified. Financial arrangements exist which make possible the prediction and budgeting for the cost of providing service. Based on its observations, the committee finds that the absence of "free choice of physician" does not necessarily result in inferior care; but the committee in no way intends to state that good quality medical care was rendered in these plans because of the absence of free choice.

\footnotetext{
${ }^{18}$ At the end of 1968 about three million persons were enrolled in the six group practice prepayment plans with enrollment exceeding 50,000. OfFice of Research and Statistics, U.S. Social. Securuty Administration, Resenrch and Stattstics Note No. I7, table 6 (1969).

${ }^{10}$ Comment, The American Medical Association: Power, Purpose, and Politics in Organized Medicine, 63 Yale L.J. 937, 976-78, 989-96 (1954); R. Harris, A Sacred Trust (r966); M. Gross, The Doctors 473-78 (i966); E. Rayacr, Professionaz Power and American Medicine: The Economics of the American Medical Association $180-95$ (I967).
} 
The committee has noted a trend toward offering the individual employee more than one plan for medical care so that he may exercise his choice. The committee believes that this development is commendable. It indicates that proponents of some closed panel plans have come to recognize the desirability of a wider choice of physician by the patient. ${ }^{20}$

Upon review of the report, the American Medical Association's House of Delegates resolved:

The American Medical Association believes that free choice of physician is the right of every individual and one which he should be free to exercise as he chooses.

Each individual should be accorded the privilege to select and change his physician at will or to select his preferred system of medical care, and the American Medical Association vigorously supports the right of the individual to choose between these alternatives. ${ }^{21}$

This, of course, does not mean that all physicians warmly embrace group practice prepayment, but the atmosphere is far less unfavorable today than it was twenty or thirty years ago, and in our judgment today's principal obstacles to the growth of group practice prepayment plans are not chargeable to organized medicine.

Probably the most important single obstacle is the difficulty of putting together the various components that must exist for a plan to develop successfully. These include adequate financing, physicians, and members. Even if all these elements are present, there remain questions of leadership and organization, particularly professional leadership and effective management.

A strong and stable group of physicians is obviously one of the most critical elements in establishing a successful plan. However, as we have suggested, able and professionally respected physicians can do very well by following established patterns, and the incentives to turn to group practice prepayment plans are perhaps less tangible than the rewards of traditional practice. There is also the factor of inertia on the part of the people who would be served, who tend to retain known and familiar arrangements in preference to something new and untried unless they have relatively strong reasons to change.

Group practice prepayment plans have also had a number of legal battles, many of them with organized medicine. ${ }^{22}$ These cases, in which the plans have in-

\footnotetext{
${ }^{20}$ Commission on Medical Care Plans, Report: Findings, Conclusions and Recommendations, J.A.M.A. (Spec. ed.), Jan. I7, I959, at 44 .

${ }^{21}$ AMA House of Delegates, as quoted in The President's Page, r70 J.A.M.A. I554 (1959).

${ }^{22}$ See Group Health Ass'n v. Moor, 24 F. Supp. 445 (D.D.C. I938), aff'd sub nom. Jordan v. Group Health Ass'n, I07 F.2d 239 (D.C. Cir. I939); United States v. American Medical Ass'n, Iro F.2d 703 (D.C. Cir.), cert. denied, 310 U.S. 644 (1940); American Medical Ass'n v. United States, I30 F.2d 233 (D.C. Cir. I942), affd, 317 U.S. 519 (I943); Group Health Cooperative v. King County Medical Soc'y, 39 Wash. 2d 586, 237 P.2d 737 (I95I); Complete Serv. Bureau v. San Diego County Medical Soc'y, 43 Cal. 2d 201, 272 P.2d 497 (I954); Comment, Medical Service Plans in California, 43 Carip. L. Rev. 674 (I955); Group Health Ins. v. Howell, 40 N.J. 436, I93 A.2d I03 (I963), and 43 N.J. I04, 202 A.2d 689 (Ig64).
} 
variably prevailed, are perhaps most noteworthy as indicating a disposition by courts to allow freedom to experiment in the development of alternative means of delivering health care services. Group practice prepayment plans also may be faced with statutory restrictions. Here again, however, courts have reached conclusions favorable to group practice prepayment plans. For example, in Complete Service Bureau v. San Diego County Medical Society, ${ }^{23}$ the California Supreme Court held that the enabling act for Blue Shield (a medical society sponsored prepayment plan) was not the exclusive vehicle for incorporation of a group practice prepayment plan, and that the general nonprofit corporation law remained available to a plan seeking to incorporate. If the result were otherwise, the plan sponsored by the medical society would exercise a monopoly. In Group Health Insurance of New Jersey v. Howell, ${ }^{24}$ the New Jersey court voided statutory restrictions that in effect gave the Medical Society of New Jersey the right to veto group practice prepayment plans. The offending provisions provided that no plan trustee could be elected unless his nomination were approved by the medical society, and that at least fifty-one per cent of the eligible physicians in any county would have to participate to qualify the plan for a certificate to do business in the county. Other states have similar provisions. $^{25}$

\section{B. Major Existing Plans}

Notwithstanding the many obstacles to development and growth of group practice prepayment plans, a number of them do exist. The six plans with more than 50,000 members are described below. ${ }^{26}$ All of them undertake to provide relatively comprehensive benefits to a relatively broad segment of the community.

A great deal of earlier legal discussion revolves about the phrase "corporate practice of medicine." The corporate practice rule was invented as a weapon to strike down arrangements that tended to commercialize the profession and to exploit the public because of a potential conflict, presumably not present in a nonprofit setting, between professional standards and the profit motive of the corporate employer. People $e x$ rel. State Bd. of Medical Examiners v. Pacific Health Corp., I2 Cal. $2 d$ I56, I6o, 82 P.2d 429, $43 \mathrm{I}$ ( 1938 ). Its fictional character is obvious; for example: "The underlying theory upon which the whole system of dental laws is framed is that the state's licensee shall possess consciousness, learning, skill and good moral character, all of which are individual characteristics, and none of which is an attribute of an artificial entity." Parker v. Board of Dental Examiners, 216 Cal. 285, 295, I4 P.2d 67, 7I (1932). See also Hansen, Group Health Plans-A Twenty-Year Legal Review, 42 MrNs. L. Rev. 527 (1958); Hansen, Legal Problems in the Organization and Operation of Group Health Plans, 5 VAND. L. Rev. I4 (I95I); Hansen, Laws Affecting Gronsp Health Plans, 35 Iowa L. REv. 209 (1950); Medical Service Plans in California, supra at 677; Laufer, Ethical and Legal Restrictions on Contract and Corporate Practice of Medicine, 6 LAw \& ConTEMP. PRoB. 516, 525-26 (1939).

${ }^{23} 43$ Cal. 2d 20r, 272 P.2d 497 (x954).

${ }^{34} 40$ N.J. 436 , I93 A.2d I03 (I963), and 43 N.J. ro4, 202 A.2d $68 \mathrm{~g}$ (I964).

${ }^{35}$ See, e.g., GA. Code ANn. tit. 56, $\$$ 56-I806 (I960); Iowa COdE ANN. \$ 514.4 (Supp. I970); Kr. Rev. Stat. \$303.I80 (I962); Rev. Codes Mont., I947, § x5-2304 (repl. vol. 2 (pt. I), I967); NEv. Rev. STAT. $\$ 696.100(1963)$. Most states have laws that limit or regulate group practice prepayment plans, but they vary widely in detail and in pattern of regulation and do not suggest any meaningful generalization.

${ }_{20}^{\circ}$ Membership figures given below are as of the summer of $197 \mathrm{I}$, when membership in these six plans totaled about 3,550,000. Although definitive data are not available, this figure probably represents in excess of $95 \%$ of the enrollment in community group practice prepayment plans. ReSEarch aNd Statistics Note No. I7, stipra note 18 , tables $5 \& 6$. 
The Health Insurance Plan of Greater New York ${ }^{27}$ was established in 1947 to arrange prepaid group medical services for New York City employees. The plan operates in New York City and its suburbs and provides coverage to 780,000 persons, including more than 80,000 Medicaid enrollees. ${ }^{28}$ Medical services are provided by thirty independent medical groups, while hospital services are provided at community hospitals and are insured by Blue Cross. The plan recently purchased a hospital and is preparing to cover hospital services for part of its membership on a direct-service basis.

The Ross-Loos Medical Group ${ }^{29}$ is a partnership of physicians which was organized in Los Angeles in 1929. The physician partners own and direct the administration of the plan. The group currently uses community hospitals but will soon build one of its own. Approximately r32,000 members are served by a medical staff of more than one hundred full time physicians plus a number of part-time physicians.

Group Health Cooperative of Puget Sound $d^{30}$ is located in Seattle and serves the Seattle metropolitan area. The plan was organized in 1947 and is operated by its cooperative members as a hospital-based group practice prepayment plan. Its comprehensive prepaid benefits include a broad outpatient prescription drug benefit that has received national attention. ${ }^{31}$ Its membership has grown substantially in recent years, and it now provides medical and hospital care to more than 143,000 persons.

Group Health Association, Inc., of Washington, D.C. was organized in 1937 as a nonprofit mutual association by a group of federal employees. The plan's conflict with the District of Columbia Medical Society and the American Medical Association represents a legal milestone in the development of prepaid group practice. ${ }^{32}$ This consumer-sponsored plan now serves more than 76,000 members. Hospital services in community hospitals are included in the plan's prepaid coverage. ${ }^{33}$

Community Health Association ${ }^{34}$ began serving members in Detroit in 1960. It was organized by the United Automobile Workers as a nonprofit unincorporated

\footnotetext{
${ }^{27}$ Daily, The Health Insurance Plan of Greater New York, ONT. Med. Rev., June x96r.

${ }^{28}$ Brindle, The Impact of Medicaid, 44 Bull. N.Y. ACAD. MEd. (2d ser.) I324 (I968).

${ }^{20}$ The Ross-Loos Medical Group, 78 CAL. MED. 477 (I953); U.S. Department of Health, Education, and Welfare, Public Health Service, Division of Medical Care Administration, The Ross-Loos Medical Group, 1967 (pilot study-not generally available).

${ }^{30}$ J. Kahl, Group Health Cooperative of Puget Sound: General Information, Apr. I963 (copies available from Group Health Cooperative of Puget Sound, Seattle, Washington).

${ }^{81}$ McCaffree \& Newman, Prepayment of Drug Costs Under a Group Practice Prepayment Plan, 58 AM. J. Pub. Health 1212 (1968).

ar Group Health Ass'n v. Moor, 24 F. Supp. 445 (D.D.C. 1938), aff'd sub nom. Jordan v. Group Health Ass'n, ro7 F.2d 239 (D.C. Cir. 1939); United States v. American Medical Ass'n, Iro F.2d 703 (D.C. Cir.), cert. denied, 3тo U.S. 644 (I940); American Medical Ass'n v. United States, I30 F.2d 233 (D.C. Cir. I942), affd, 3 I7 U.S. 519 (I943).

${ }^{33}$ Watters, Group Health Association, Inc., of Washington, D.C., ro Group Practice 66r (xg6r); Group Health Association, Annual Report, 32 G.H.A. NEws I (1969).

${ }^{36}$ Mott, Community Health Association of Detroit, in Proceedings of the Eleventh Annual Group Health INstitute (Group Health Association of America, I96r).
} 
membership organization. ${ }^{35}$ Community Health Association contracts with Metropolitan Hospitals and Clinics, a nonprofit organization which includes a general hospital and a full-time medical group for the provision of covered hospital and medical services. It now serves approximately 70,000 persons.

Kaiser Foundation Health Plan ${ }^{36}$ arranges medical and hospital care for more than 2,247,000 members in the six geographic areas it serves: the San Francisco BaySacramento area $(x, 000,000)$; the Los Angeles-San Diego area (946,000); the Portland-Vancouver metropolitan area (I49,000); the Island of Oahu, Hawaii (90,000); Cleveland metropolitan area $(46,000)$; and the Denver metropolitan area $(16,500)$. Kaiser Foundation Health Plan contracts with an independent group of physicians in each of these six areas. Each of the six medical groups undertakes to provide or arrange all covered professional services for plan members. The plan contracts with Kaiser Foundation Hospitals in California, Oregon, and Hawaii for the provision of covered hospital services to members. In Cleveland, where the plan assumed operation of another group practice prepayment plan on January $\mathrm{r}$, $1969,{ }^{37}$ most hospital services are provided in community hospitals; however, Kaiser Foundation Hospitals now has one hospital serving Health Plan members in the Cleveland area, and future plans call for most hospitalization to be provided by Kaiser Foundation Hospitals. In Denver, where a new plan was started on July $I$, I969, community hospitals are providing hospital services to plan members.

The program originated as a means of providing comprehensive medical care to Kaiser industrial employees and their families in remote areas and in other areas where medical services were in short supply. This nonprofit program has applied many aspects of industrial management to the health care field, and the strength of its management, including medical group management, has contributed significantly to its success. The program has pragmatically evolved into a large-scale community medical care program that is self-sustaining and that finances its own growth in its

\footnotetext{
${ }^{85}$ Mott \& Hudenburg, Labor's Influence on Health Care Developments (pts. I-3), Hospital MaNAGEMENT, Oct. 1959, at 42, Nov. 1959, at 39, Dec. 1959, at 52.

${ }^{30}$ See ig60-68 Kaiser foundation Medical Care Program Annual Reports. The ig6o and ig65 Annual Reports include summaries of the program's organization and basic principles. See also Weissman, Origins of the Kaiser Foundation Health Plan Program, in Proceedings of the Nintai ANnual. Grour Health Institure 39-42 (Group Health Association of America, 1959); Saward, Blank \& Greenlick, Documentation of Twenty Years of Operation and Growth of a Prepaid Group Practice Plan, 6 Med. CARE 231 (1968); D. Wagster, Kaiser Foundation Health Plan: A Study in Growth, address before the annual conference of the National Foundation of Health, Welfare and Pension Plans, Inc., New York City, Aug. 25, 1969 (copy in the files of Kaiser Foundation Health Plan, Inc.); I Health MaNpowER RePort, supra note 1 , at 65-69; 2 id. app. IV, at $297-228$ (Appendix IV includes a description of the Kaiser Foundation Medical Care Program). See also Cutting, supra note 4; Saward, The Relevance of Prepaid Group Practice to the Effective Delivery of Health Services, in PROcEedings of THE EIGHTEENTH Annual Group Heatth Institute 24-33 (Group Health Assaciation of America, x968); A. Weissman, Kaiser Foundation Medical Care Program, address before the New England Hospital Assembly, Boston, Mass., Mar. 24, 1970 (copy in the files of Kaiser Foundation Health Plan, Inc.).

${ }^{37}$ A. Yedidia, Planning and Implementation of the Community Health Foundation of Cleveland, Ohto (U.S. Public Health Service Publication No. 1664-3, 1968). This is the most complete description available of the development of a group practice prepayment plan.
} 
established areas of operation. Today, twenty-five years after the plan became avail. able to the public, less than three per cent of the members served are Kaiser industrial employees and their families. Because over eighty per cent of its members are drawn from employed groups of workers and their families, the program's growth is directly related to its ability to participate in group enrollment through dual or multiple choice programs. Net transfers during open enrollment periods ${ }^{38}$ consistently favor the plan by substantial margins.

A fundamental element in the plan's success has been the development and implementation of a mutuality of interest between the lay management of Kaiser Foundation Health Plan and Kaiser Foundation Hospitals and the management of the contracting medical groups. The future of both is dependent upon the financial success of a program that is structured to provide an incentive to control costs and to meet the health care needs of the members. The medical groups recognize that the lay management is responsible for obtaining members, constructing the facilities needed to serve the members, and financing the program, and the lay management recognizes that all professional matters relating to the practice of medicine must be controlled by the medical groups. ${ }^{30}$ In practice, however, matters not relating to actual care of patients are approached and resolved on a cooperative basis.

\section{Future Prospects}

The need to improve the efficiency of the health care industry in the United States is now widely recognized. One of the most frequently suggested solutions is to provide more medical care through group practice prepayment arrangements, and a number of medical schools, Blue Cross plans, and commercial insurance companies have recently joined the effort to develop more group practice prepayment plans.

The Harvard Community Health Plan, organized by the Harvard Medical School with assistance from Blue Cross and several insurance companies, started providing services in October I969. The same month Columbia Medical and Hospital Plan, which was organized by the Connecticut General Life Insurance Company and the Johns Hopkins School of Medicine, began providing services through a group practice prepayment plan in Columbia, Maryland. The Rhode Island Group Health Association, a union sponsored program, began operations in Providence, Rhode Island, on June $x$, I97r. Additional medical schools, Blue Cross plans, and major hospitals throughout the United States are now talking about developing or participating in new plans.

The U.S. Department of Health, Education, and Welfare is affirmatively en-

\footnotetext{
${ }^{38}$ In this context the term "open enrollment periods" identifies the times during which persons covered under dual-choice programs have an opportunity to change their enrollment to one of the alternate plans offered. Open enrollment periods usually occur annually.

${ }^{30} 2$ HEAITH MANPOWER REPORT, supta note $\mathrm{I}$, app. IV, at 198.
} 
couraging the development of new plans. A substantial grant has been made to the Group Health Association of America to organize community support for group practice prepayment in up to twenty-four population centers. Community organizers financed by this grant are promoting the establishment of plans in nine cities. Financial support for this program during the current fiscal year has been substantially increased. The Department also is supporting an amendment to the Medicare Act and other legislation that is intended to create financial incentives to establish organized systems of health care such as group practice prepayment plans. ${ }^{40}$

\section{Organized Health Care for the Disadvantaged}

Group practice prepayment plans, originally developed to provide health care to employed persons and their families, have recognized their responsibility and capacity to organize effective health services for the indigent. Although their role in organizing health care services for the economically disadvantaged is still evolving, these programs are demonstrating that they can organize and deliver good health care to the indigent without maintaining the usual separation of medical care for the underprivileged from medical care for the self-supporting.

The Health Insurance Plan of Greater New York, ${ }^{\mathbf{1 1}}$ Kaiser Foundation Health Plan of Oregon, ${ }^{42}$ and Group Health Cooperative of Puget Sound, ${ }^{43}$ as well as a number of smaller plans, are operating successful health care programs for indigent persons. Each of these programs includes comprehensive inpatient and outpatient health services, the care of indigent and self-supporting populations by the same

\footnotetext{
${ }^{10}$ Social Security Amendments of r971, H.R. x, 92d Cong., Ist Sess. (passed by the House, June 22, I97X).

${ }^{\prime 1}$ The Health Insurance Plan of Greater New York (HIP) began serving approximately 13,000 public assistance recipients in New York City under a demonstration program in 1962 . With the enactment of Medicaid, the program was broadened in November 1966 to include hospital care, and additional beneficiaries were enrolled. HIP now serves approximately 80,000 Medicaid beneficiaries, who are an integral part of the HIP program. Attainment of this objective required an extensive educational effort relating to health and the use of the HIP system. The program has been troubled by fluctuations in financial support and limited availability of hospital beds for patients of HIIP physicians. See Brindle, The Impact of Medicaid, 44 Bulc. N.Y. Acad. Med. (2d ser.) I324 (1968); Daily, The Health Insurance Plan-New York City Welfare Department Project, 53 AM. J. PuB. HeALTH I353 (I963); Shapiro et al., Patterns of Medical Use by the Indigent Aged Under Two Systems of Medical Care, 57 AM. J. Pub. Health 784 (1967).

${ }^{4}$ Kaiser Foundation Health Plan of Oregon, operating under an OEO grant, integrated an indigent population in Portland, Oregon, into its organized health care system in October 1967 . The original grant, which provided for the enrollment of r200 families, has been expanded to cover I500 enrolled families, or nearly 7000 persons. Comprehensive services, including hospitalization, are provided. The OEO beneficiaries receive care at the facilities which serve the program's other members. Iimited dental service is now available, and arrangements will soon be completed for more extensive dental care for this population. See Colombo, Saward \& Greenlick, The Integration of an OEO Health Program into a Prepaid Comprehensive Group Practice Plan, 59 AM. J. PuB. Health 64I (I969).

${ }^{43}$ Group Health Cooperative of Puget Sound has contracted with the Washington State Department of Public Assistance to provide comprehensive services to rooo indigent families in Seattle, Washington. Services to the nearly 4000 persons covered under this program commenced in November 1969. Comprehensive inpatient and outpatient services are delivered at the Cooperative's facilities. The Hawaii Region of the Kaiser-Permanente Program began providing services on May I, I97I, to a Medicaid population that will reach a total of 500 families.
} 
physicians in the same facilities, and the use in varying degrees of community workers, transportation aides, and health education to help the covered populations use the plans effectively. Additional programs for indigent or medically indigent persons will be undertaken in the near future. ${ }^{44}$

In addition to organization and accessibility of services, delivery of effective health care to the disadvantaged requires adequate and stable financing, a characteristic that has been notably lacking in Medicaid and other government programs. Some proposals for national health insurance would eliminate the indigent as a special category and would provide the continuity of financing that would facilitate the effective organization of services for the indigent population.

\section{III}

\section{Group Practice Prepayment and National Health Insurance}

The possibility that some national health insurance program will become effective within the next few years suggests a number of policy considerations that have particular relevance for group practice prepayment plans. It is not our purpose to evaluate various national health insurance proposals or to advocate any of them. Rather, we will attempt to identify some considerations and questions whose resolution will influence, if not determine, the place that will be occupied in the coming years by group practice prepayment plans and other nontraditional approaches to organizing and delivering health services.

\section{A. Basic Premises}

Recent ${ }^{45}$ discussions of national health insurance proposals have been substantially free of the rhetoric that predominated during the late I940s, when opponents of compulsory health insurance labeled it "socialized medicine" and implied that any large-scale national health insurance program would bring legions of meddling bureaucrats into every doctor's office and every hospital room in the country. The role of the federal government under any of the several national health insurance

\footnotetext{
4t The Kaiser-Permanente Medical Care Program's Southern California Region recently reccived an OEO grant to develop a health care program providing comprehensive benefits to 500 low-income families in the Fontana area. Services began in the fall of 1970. This region already is providing comprehensive services as part of an OEO Parent-Child Center project to yoo low-income families who reside near the program's Harbor City Hospital in Los Angeles. A prepaid dental group provides dental services to this Parent-Child Center population on a per capita basis.

The Health Insurance Plan of Greater New York has received an OEO grant to develop a comprehensive health care delivery system for 2500 poor persons residing in the western part of Suffolk County, New York. Group Health Cooperative of Puget Sound, under an agreement with the Model Cities Program in Seattle, began providing health care in late $19 \% 0$ to 500 families with an income just above the public assistance level. Group Health Cooperative also provides benefits to approximately 2,000 poor persons under an OEO grant. A number of other plans are working toward implementation of programs to serve indigent populations.

${ }^{4}$ We refer to the period from November 1968, when the late Walter P. Reuther addressed the American Public Health Association, through mid-summer 197r. See Reuther, The Health Care Crisis: Where Do We Go from Here?, 59 AM. J. Pub. Health 12 (1969).
} 
proposals that have been advanced recently would be as a purchaser of health services rather than as a provider. ${ }^{46}$ Thus we suggest that any consideration of national health policy begins with the premise that the federal government is the country's principal purchaser of health care and that its purchases will not only continue but probably will increase.

A second recommended premise, perhaps less apparent but in our judgment equally true, is that the method of payment for health services always influences, and in many cases determines, the manner in which health services are organized (or not organized) and that integration of payment for services is essential to the successful integration of the services themselves. ${ }^{47}$ For example, Medicare, rather than supporting development of better organized approaches to delivering health care, is geared to the dominant fee-for-service model that treats health care as a collection of discrete, compartmentalized services; rather than utilizing the government's purchasing power to encourage departure from traditional patterns and to promote development of alternative health care delivery systems, Medicare simply pumps more money into existing fee-for-service channels and, if anything, operates as a counter-incentive to any approach not in the fee-for-service mold.

Group practice prepayment plans have encountered some difficulty in attempting to conform to Medicare's requirements. ${ }^{48}$ These plans depend upon a predictable and continuing income flow in planning and organizing comprehensive health care services, but Medicare's fee-for-service method of payment may or may not provide the income required to support a service capability which is developed

\footnotetext{
"The term "socialized medicine"-if used to describe a system whereby the government is the direct provider of health care services, the owner of all hospitals, and the employer of all physicians and allied personnel-obviously is not appropriate when applied to any of the current proposals. The principal areas of difference among national health insurance proposals relate to financing (including the question of voluntary or compulsory participation), comprehensiveness of benefits and persons covered, the use or nonuse of existing voluntary health insurance mechanisms, and the manner in which the program would be administered.

"Erickson, The Impact of Medicare on a Group Practice Prepayment Plan, 44 BulL. N.Y. ACAD. MED. (2d ser.) I3I2, I3I3-I4 (Ig68).

48 "Fitting a group practice prepayment plan into the essentially alien pattern of the fee-forservice Medicare program posed serious administrative problems. Obviously, indemnity cash payments on the basis of the number of services rendered to each individual, claims processing, paper collection, deductibles, coinsurance and other fee-for-service concepts that were incorporated into Medicare were not consistent with the operations or principles of group practice prepayment programs. We [the Kaiser-Permanente Medical Care Program] were required to generate a great deal of additional information to meet the communication, reimbursement, administrative, and statistical requirements of the Social Security Administration. A substantial amount of this additional information was foreign to the normal operation of a group practice prepayment plan. Consequently collection of the data required the development of new systems, extensive training of personnel, and the employment of some additional personnel.

"These administrative requirements have been unduly costly in time, money, and resources. They have made no contribution to the provision of health services, and they have interfered with some of the basic operational advantages of our plan."

Id. at I377. Moreover, the division of Medicare into part A benefits (essentially institutional services) and part $B$ benefits (essentially physicians' and related noninstitutional services) reinforces the artificial dichotomy between "in-hospital" and "out-of-hospital" services. See note I2 supra.
} 
and maintained, irrespective of utilization, for the benefit of the defined population that the plan undertakes to serve. A useful start toward harmonizing Medicare with the operations of group practice prepayment plans would be to allow these plans to receive a fixed per capita payment for both the part $A$ and part $B$ Medicare services they offer. This would permit group practice prepayment plans to operate in a manner that is compatible with their fundamental principles.

\section{B. Some Fundamental Considerations}

Rather than simply providing additional sums in support of the status quo, the government's health care purchasing power should be employed to assure greater choice for consumers of health services and at the same time to provide an opportunity for development and growth of different and less costly approaches to organizing and delivering these services. Specifically, we direct attention to four elements that would help assure a more effective national health insurance program: $:^{40}$ (I) a pluralistic environment, in which diversity and innovation are encouraged and in which both consumers and providers have significantly different alternatives available; (2) incentives to consumers to participate in organized programs; (3) incentives to providers to participate in organized programs; and (4) assurance that the capital needs of organized programs will be effectively met.

\section{A Pluralistic Environment}

First, any national program should provide a basis for a pluralistic system, permitting diversity and innovation and providing an opportunity for consumers to select from among significantly different alternative arrangements for obtaining health care services. A program that fails to encourage experimentation and diversity will, by default, sustain and perpetuate the present system.

Without advocating any particular approach, it is possible to identify programs that incorporate features supporting experimentation and diversity. The Federal Employees Health Benefits Program ${ }^{50}$ is the largest and probably best known. Under this multiple-choice program, ${ }^{51}$ called by one observer "a creative, pragmatic, mix of public and private initiative," ${ }^{25}$ the government, as employer, contributes a fixed amount toward the cost of coverage for each employee and his eligible dependents. The additional charge, roughly sixty per cent of the total, is paid by the employee.

This program has a number of elements that could be productively emulated

${ }^{40}$ These four points were presented by C. Keene, Bench Marks for National Insurance, in PROCEEDINGS of THE 20TH ANNUAL Group Health INSTItUTe 48-53 (Group Health Association of America, I970).

${ }_{50} 5$ U.S.C. $\$ 890$ I et seq. (Supp. IV, I969).

${ }^{8}$ See text accompanying notes 7-Io supra.

${ }^{82}$ A. Somers, National Health Insurance: Major Proposals and Issues, address delivered at a mecting on 'National Health Insurance-A Matter of Importance in the '70's," sponsored by the Women's Executive Committee of the United Hospital Fund of New York, Jan. 29, 1970, at $1_{3}$ (copy in the files of Kaiser Foundation Health Plan, Inc.). 
on a broader basis. First, it offers the consumers a choice of plan. ${ }^{53}$ Second, programs that offer a choice provide an opportunity for testing new health care delivery arrangements and a corresponding potential for reshaping the delivery system. Although competition among providers themselves is not a reliable costcontrol factor for a number of reasons, ${ }^{54}$ programs that provide a choice to participants involve significant competition among the alternative approaches represented by the participating plans. Competition among the plans themselves, coupled with a contribution by payroll deduction to cover the balance of the premium for the plan selected, may operate as constraints on costs. It has also been pointed out that adoption of a program that offers a choice would not involve an irrevocable commitment to any single approach. ${ }^{55}$

\section{Incentives to Consumers}

National health insurance will not promote development of more effective health delivery systems unless it provides clear and persuasive inducements to individual beneficiaries to associate themselves with effective systems. Hence a national program should embody substantial reasons why consumers-the people to be served -should prefer to associate themselves with an organized delivery system.

We have stated that the most significant characteristic of group practice prepayment plans is acceptance of responsibility for the organization and delivery of health care services to a defined population. A correlative limitation is that the enrolled population forgoes its freedom to obtain reimbursement for the cost of services it may obtain from sources outside the program. In the absence of specific and perceivable advantages under the organized program-such as more comprehensive coverage, greater accessibility, greater assurance of quality of care,

\footnotetext{
Es "Although there can be no doubt that the 'single-plan' approach would have been most desirable from the standpoint of administrative simplicity, now that we have learned to live with the administrative problems which stem from multiple choice it becomes equally clear that the wide choice of plans has produced a program which is more effective in meeting the needs of Federal employees and their dependents."

A. Ruddock, Federal Employees Health Benefits Program, address before the Joint Session of the Medical Care Section of the American Public Health Association and the Group Health Association of America, A.P.H.A. Annual Meeting, New York City, Oct. 7, 1964 (copy in the files of Kaiser Foundation Health Plan, Inc.).

ot People generally do not shop for a physician on the basis of price. Hospitalization normally occurs at the time and place directed by the physician and the patient usually has little part in the decision. When the cost of care is prepaid, the patient's interest in the cost of the care he receives is indirect, and the cost of his care does not noticeably influence the cost of his prepaid coverage. Finally, reimbursement formulas that are based upon cost provide little incentive to control cost.

Es "An FEP-type program appears to offer greater possibility of both short-run cost controls and long-run adjustments in the delivery system.

"If, on the other hand, these hopes do not materialize; if, in fact, the private carriers prove unable to exert effective cost pressures on the providers and the necessary adjustments in delivery are not forthcomirg, the decision is not irrevocable. Private underwriting can be terminated and the voluntary carriers assimilated into a governmental system far more easily than the reverse. In short, this method appears to provide maximum flexibility and maneuverability to enable the program to meet future developments without giving irretrievable hostages to fate."

Address by A. Somers, supra note 52, at 20-21.
} 
or lower costs-few individuals would sacrifice their freedom to obtain services elsewhere. For a specific individual the over-all social advantages of an organized delivery system would almost certainly be outweighed by the personal advantage of unrestricted freedom of choice.

What incentives could be provided to consumers to enroll in a group practice prepayment plan? At the outset we assume that organized systems can offer equal benefits at a cost lower than could be realized under prevailing health care arrangements. $^{56}$ If a national health insurance program should leave some services uncovered, one approach to providing consumer incentives would be to make these savings available to the organized program in order that it could provide supplemental benefits to its enrolled population. An excellent measure of the effectiveness of organized health systems would be seen in what they could accomplish with the same amount of money per covered individual as is available to unorganized sources of care in the same general geographical area.

\section{Incentives to Providers}

Just as a national health program should provide incentives to individual beneficiaries to associate themselves with organized systems, it should also offer incentives to providers of care-physicians, supporting personnel, hospitals, and other health care institutions-to participate in organized systems. Although it is widely recognized that effective organization for the delivery of health care services is essential if our national health care objectives are to be achieved at reasonable cost, little improvement will occur unless physicians and other providers of health care services commit themselves to the successful development of the improved delivery systems that we know are needed.

History suggests the need for provider incentives. We have yet to see a major fee-for-service medical group or traditional hospital reorganize to devote its primary efforts to providing comprehensive health care to a prepaid population. Any physician or hospital undertaking to participate in an organized program must sacrifice some measure of autonomy and subordinate some individual or institutional aspirations to the interests of the program and the welfare of its beneficiaries. For example, a hospital operating within an organized program may not undertake a facility expansion or emphasize or abandon a service (such as a maternity department) without consideration of the capital resources and facility

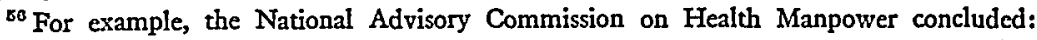

"Compared to the California averages, Kaiser had significantly fewer hospital beds and physicians per member served; and for roughly comparable medical services, Kaiser expenses per member are 35-45 percent less than the expenses of the average Californian. Not all of this difference represents a true economy of Kaiser. First, Kaiser members obtain some of the medical care outside of the Kaiser Plan, thus reducing Kaiser expense per member. Second, indigents and old persons are underrepresented in Kaiser compared to the State's population. Still, after making allowances for these factors, it appears that the cost to the average person who obtains medical care through Kaiser is 20-30 percent less than it would be if he obtained it outside."

2 HEALTH MANPOWER Report, supra note I, app. IV, at 206-0\%.
} 
and service needs of the program as a whole. Although there are instances of existing hospitals being purchased by group practice prepayment programs, and examples of cooperation between established hospitals and group practice prepayment programs, we know of no instance in which an established hospital and its medical staff have significantly reshaped their organization and redirected their efforts to emphasize service to an enrolled population on a prepaid basis.

We suggested above that savings achieved by an organized program could be used to provide supplemental benefits to the program's beneficiaries. A portion of the savings could also be made available to the program itself through earmarked subsidies for specified purposes, such as testing new methods for more efficient utilization of manpower. Other approaches could involve direct subsidies to institutional providers participating in organized programs or indirect subsidies through tax-favored retirement and related benefit programs for persons dedicating their professional careers to the care of persons enrolled in organized programs.

\section{Satisfying Capital Requirements}

An organized health care program requires capital to obtain and maintain facilities and equipment and to keep pace with developing health care technology. In the case of new programs, capital is also required for organizational and start-up costs. Thus, any national program should include adequate provision for the major capital investments required to finance the development and expansion of organized and effective health care delivery systems.

Methods of paying for services may be designed and adjusted either to encourage or to discourage this kind of development. Medicare illustrates an approach tending to discourage it. Medicare does not allow any return on capital for nonprofit institutions, although a return on equity capital is assured to proprietary institutions. ${ }^{57}$ During times of rising costs the cash generated through an allowance for depreciation alone is grossly inadequate to finance even replacement, let alone expansion.

In contrast, under the Federal Employees Health Benefits Program and other multiple or dual choice arrangements, participating organizations that operate efficiently and satisfy their consumers have an opportunity to generate funds for their growth and development. Although this approach does not resolve all capital financing issues and, in particular, would not meet the needs of new plans, it does inject a vital selective factor, both to encourage the development of effective health care delivery systems and to reward and thereby promote the growth of the more effective systems.

57 "The amount allowable on an annual basis is determined by applying to the provider's equity capital a percentage equal to one and one-half times the average of the rates of interest on special issues of public debt obligations issued to the Federal Hospital Insurance Trust Fund for each of the months during the provider's reporting period or portion thereof covered under the program."

20 C.F.R. $\$ 405.429$ (a) (1970). The rate of return has averaged over I0\%. Table of Interest Rates for Proprietary Providers' Returns on Equity Capital, May r969. 


\section{Conclusion}

We have described the group practice prepayment approach to the organization and delivery of health care services and identified some issues of governmental policy which appear, from the viewpoint of persons involved in group practice prepayment, to be especially significant for the future development of this particular type of health system. Group practice prepayment is just one alternative, and there are other approaches-no doubt some not yet formulated-to the objective of effective and efficient application of resources to meet the health care needs of our total population. It is against this objective that the policies of the health care industry and proposals for further governmental action must ultimately be judged. 